\title{
Effect of Ankle-foot Orthosis on Lower Limb Muscle Activities and Static Balance of Stroke Patients Authors' Names
}

\author{
Youngmin Lee, MSc, PT ${ }^{1)}$, Jin Gang Her, PhD, $\left.\mathrm{PT}^{2}\right)^{*}$, Youngeun Choi, $\mathrm{PhD}, \mathrm{PT}^{1)}$, \\ HeEsoo Kim, PhD, $\mathrm{OT}^{1)}$ \\ 1) Department of Rehabilitation Therapy, Graduate School of Hallym University, Republic of Korea \\ 2) Department of Physical Therapy, Hallym College: Janghak-ri, Dong-myeon, Chuncheon-si, \\ Gangwon-do 200-711, Republic Korea
}

\begin{abstract}
Purpose] This study examined the effects of an ankle-foot orthosis worn during balance training on lower limb muscle activity and static balance of chronic stroke patients. [Subjects] The subjects were twenty-five inpatients receiving physical therapy for chronic stroke. [Methods] The chronic stroke patients were divided into two groups: thirteen patients were assigned to the ankle-foot orthosis group, while the remaining twelve patients wore only their shoes. Each group performed balance training for 20 minutes, twice per day, 5 days per week, for 6 weeks. The lower limb muscle activities of the paralyzed side tibialis anterior, medial gastrocnemius, and the stability index were measured before and after the 6-week intervention. [Results] Comparison of the groups indicated a significant difference in the muscle activity of the paralyzed side tibialis anterior and the stability index of the eyesopen standing position. After the intervention, the ankle-foot orthosis group evidenced a significant difference in the muscle activities of the paralyzed side tibialis anterior and paralyzed side medial gastrocnemius as well as the stability index of the eyes-open standing position, eyes-closed standing position, eyes-open standing position on a sponge, and eyes-closed standing position on a sponge. The group that only wore their shoes showed significant differences in the stability indexes of eyes-open standing and eyes-open standing on a sponge. [Conclusion] Using the ankle-foot orthosis was effective during the initial training of lower limb muscle activities and the static balance training of chronic stroke patients. However, it was not effective for a variety of dynamic situations.

Key words: Ankle-foot orthosis, Lower limb muscle activity, Static balance
\end{abstract}

(This article was submitted Jun. 7, 2013, and was accepted Aug. 25, 2013)

\section{INTRODUCTION}

Stroke patients are characterized by an asymmetric posture due to decreased movement, and this asymmetric posture makes balance control in a standing posture difficult, as a result of the center of pressure moving toward the lower limb of the unaffected side, triggering problems with postural control ability ${ }^{1)}$. Loss of balance ability in stroke patients may cause increased postural sway, reduction of weight on the lower limb of the affected side, and increased fall risk $^{2)}$.

In general, balance or postural stability refers to maintaining the center of mass within the support surface to maintain static action and to perform desired motions. Balance ability is essential for functional activities, as well as for actions such as sitting, standing, and walking ${ }^{3)}$. To maintain and adjust balance, the proprioceptive, visual, and

\footnotetext{
*Corresponding author. Jin Gang Her (E-mail: jghur7@, empas.com)

C2014 The Society of Physical Therapy Science. Published by IPEC Inc. This is an open-access article distributed under the terms of the Creative Commons Attribution Non-Commercial No Derivatives (by-ncnd) License $<$ http://creativecommons.org/licenses/by-nc-nd/3.0/> .
}

vestibular senses must interact ${ }^{4}$. However, $65 \%$ of stroke patients experience loss of tactile and proprioceptive senses, largely because of impaired in proprioception resulting from lowered muscle tone ${ }^{5)}$.

Various methods exist to resolve problems of balance of stroke patients. These include therapeutic exercises, such as weight shifting to the lower limb of the affected side, proprioceptive neuromuscular facilitation techniques, Bobath techniques, neurodevelopmental facilitation techniques, and task-oriented exercises ${ }^{6,7)}$. Repetitive exercise is necessary to improve balance, and ankle-foot orthoses are used for hours when there is excessive spasticity or deformity. Ankle orthoses stabilize the ankle joint and compensate for insufficient ankle dorsiflexion and mediolateral instability of the subtalar joint, increasing balance ability. They also facilitate medial shift of the center of mass and weight shift toward the foot of the affected side, reducing asymmetric body posture ${ }^{8)}$.

Dysfunction of the foot and the ankle joint of stroke patients are closely associated with functional and kinetic aspects of the lumbar region and lower limbs, inevitably triggering overall body imbalance ${ }^{9)}$. The ankle joint and the hip joint play important roles in providing body stability during stroke patients' balance training. The first type of postural control strategy is the ankle joint strategy, which primarily 
improves standing balance through muscle contraction of the ankle joint ${ }^{10)}$.

While walking with an ankle-foot orthosis, the moment of the dorsiflexion angle during the stance phase and plantarflexion during the terminal stance may increase ${ }^{11)}$. In a static standing position, the ankle joint is used frequently ${ }^{12}$, and according to comparisons of muscular strength between those who have experienced falls and those who have not, the extensors of the hip joint and the plantar flexor of the ankle joint show significant differences ${ }^{13}$, indicating that loss of balance ability is closely related to the weakening of ankle strength ${ }^{14)}$. Therefore, the purpose of this study was to examine the effects of balance training with an anklefoot orthosis on stroke patients' lower limb muscle activities and static balance maintenance.

\section{SUBJECTS AND METHODS}

The subjects of this study were 25 stroke patients, and they were randomly assigned to a group with ankle-foot orthosis shoes (AFO, $n=13)$ and a group with shoes $(n=12)$ (Table 1). Prior to participation in this study, the purpose was explained to the subjects and their guardians, and they consented to participate voluntarily. The research and development review board for human subjects of Hallym University approved this study. All procedures conformed to the ethical principles of the Declaration of Helsinki. Inclusion criteria were: a diagnosis of stroke within the previous 6-12 months; no evidence of vestibular system disorders, neurological deficits in the bilateral lower limbs, or visual or auditory disorders; a mini-mental state examination-Korean score of 23 or higher; a Berg Balance Scale score of 40 or higher without any musculoskeletal deficit that affected standing balance; and agreement to wear a plastic anklefoot orthosis of the plantar flexion $90^{\circ}$ ankle stop-type.

A Tele Myo 2400T dynamic electromyograph (EMG, Noraxon Inc. Arizona, USA) was employed to measure muscle activities of the lower limbs. The electrodes were attached to the affected side over the tibialis anterior muscle at one-third of the distance from the proximal tibialis anterior muscle, and the muscle belly of the medial gastrocnemius muscle $2 \mathrm{~cm}$ proximal from where the Achilles tendon encounters the medial gastrocnemius muscle. The collected surface EMG signals were digitized using MyoresearchXP 1.07 software: EMG signals were sampled at $1000 \mathrm{~Hz}$, bandpass-filtered between 20 to $500 \mathrm{~Hz}$, and processed with a $60 \mathrm{~Hz}$ notch filter.

A Tetrax Portable Multiple System (Tetrax, Tetrax Ltd, Ramat Gan, Israel) was used to measure balance ability ${ }^{15)}$. When a subject places a foot on the force plate, the data of the pressure on the force plate is amplified and filtered before being delivered to a computer. It is then analyzed using the Tetrax software program. For the measurement of static balance ability, the stability index was obtained, and the collected data were recorded as percentages of the subjects' body weights.

The ankle-foot orthosis used in this study was a joint type, and it was appended and raised by $1 / 8$ of an inch so that the medial malleolus and the lateral malleolus did not meet, and the arch support maintained or supported the
Table 1. The general characteristics of the subjects

\begin{tabular}{lcc}
\hline \multirow{2}{*}{ Variables } & \multicolumn{2}{c}{ Group } \\
\cline { 2 - 3 } & $\begin{array}{c}\text { AFO Group } \\
(\mathrm{n}=13)\end{array}$ & $\begin{array}{c}\text { Shoes Group } \\
(\mathrm{n}=12)\end{array}$ \\
\hline Sex & & \\
Male & $5(38.5 \%)$ & $4(33.3 \%)$ \\
$\quad$ Female & $8(61.5 \%)$ & $8(66.7 \%)$ \\
Diagnosis & & \\
Infarction & $5(38.5 \%)$ & $3(25 \%)$ \\
Hemorrhage & $8(61.5 \%)$ & $9(75 \%)$ \\
Affected side & & \\
Left & $10(76.9 \%)$ & $7(58.3 \%)$ \\
Right & $3(23.1 \%)$ & $5(41.7 \%)$ \\
Onset time (months) & $9.0 \pm 1.2$ & $9.9 \pm 1.0$ \\
Age (years) & $58.9 \pm 5.5$ & $57.2 \pm 4.4$ \\
Height (cm) & $160.8 \pm 8.5$ & $159.2 \pm 7.4$ \\
Weight (kg) & $56.6 \pm 8.5$ & $57.2 \pm 8.2$ \\
Ashworth scale & & \\
Gastrocnemius & $2 \pm 1$ & $2 \pm 1$ \\
\hline
\end{tabular}

Values are number (\%) or mean $\pm \mathrm{SD}$

longitudinal arch when it was worn. The medial and lateral sides of the caput metatarsals tend to widen when they support weight; therefore, each of the medial sides and the lateral sides were widened by $1 / 16$ inch and the orthosis was made to be a plantar flexion $90^{\circ}$ ankle stop-type using a $5 \mathrm{~mm}$ thick thermoplastic material that melted at $170{ }^{\circ} \mathrm{C}$. The shoes were made of rubber so as not to slide. Bands wrapped around the top of the shoes so that they were not easy to remove, and they were made lightweight so that they could be used indoors.

Prior to and after the balance training, muscle activities and balance ability were measured. Four balance exercises were conducted, two on flat ground and two on a balance pad (balance pad, Airex, Switzerland) for a total of $20 \mathrm{~min}$ utes $(\text { Table } 2)^{16,17)}$.

To measure the muscle activities in a standing position, the subject maintained a standing position in bare feet for five seconds. Data were recorded for three seconds from the tibialis anterior muscle and the medial gastrocnemius muscle of the affected side; the first and the last one seconds were excluded from the data analysis. Muscle activity signals of each muscle were converted to root mean square values, and expressed as \% maximum voluntary isometric contraction (\%MVIC).

For the measurement of balance ability, the subjects stood on a hard surface with their eyes open and with their eyes closed and on a soft pillow with their eyes open and with their eyes closed. They maintained the standing position without holding a support. Measurements were made three times in each position, and the average values were used the analysis.

The statistical analysis of this study was performed using PASW 18.0. We used the independent t-test to compare differences between the two groups, and the paired t-test to compare within-group differences, before and after the intervention. Significance was accepted for values of $p<0.05$. 
Table 2. Program for balance training

\begin{tabular}{lllcc}
\hline Period & Composition & Training methods & Time & Rest \\
\hline \multirow{3}{*}{$0-6$} & & Standing on two feet & $1 \mathrm{~m}$ & $15 \mathrm{~s}$ \\
weeks & \multirow{2}{*}{ On the floor } & Standing with both knees flexed & $1 \mathrm{~m}$ & $15 \mathrm{~s}$ \\
& & Standing on the affected leg while holding a chair with the unaffected arm & $1 \mathrm{~m}$ & $15 \mathrm{~s}$ \\
& & Alternate leg raise: standing on a foothold $20 \mathrm{~cm}$ high & $1 \mathrm{~m}$ & $15 \mathrm{~s}$ \\
& & Standing on two feet & $1 \mathrm{~m}$ & $15 \mathrm{~s}$ \\
$0-6$ & \multirow{2}{*}{ On a balance pad } & Standing with both knees flexed & $1 \mathrm{~m}$ & $15 \mathrm{~s}$ \\
weeks & & Standing on the affected leg while holding a chair with the unaffected arm & $1 \mathrm{~m}$ & $15 \mathrm{~s}$ \\
& & Alternate leg raise: standing on a foothold $20 \mathrm{~cm}$ high & $1 \mathrm{~m}$ & $15 \mathrm{~s}$ \\
\hline
\end{tabular}

Table 3. Comparison of muscle activities between the two groups

\begin{tabular}{|c|c|c|c|}
\hline \multirow{2}{*}{ Variables } & & \multicolumn{2}{|c|}{ Group } \\
\hline & & AFO Group $(n=13)$ & Shoes Group $(n=12)$ \\
\hline \multirow{3}{*}{ PTA $(\%)$} & Pre- & $19.93 \pm 4.85$ & $20.26 \pm 3.83$ \\
\hline & Post- & $16.71 \pm 3.88$ & $20.23 \pm 3.49$ \\
\hline & Change $^{* *}$ & $-3.22 \pm 0.57^{*}$ & $-0.03 \pm 0.49$ \\
\hline \multirow{3}{*}{$\begin{array}{l}\text { PMG } \\
(\%)\end{array}$} & Pre- & $23.65 \pm 8.10$ & $24.87 \pm 4.59$ \\
\hline & Post- & $26.64 \pm 5.83$ & $25.51 \pm 5.11$ \\
\hline & Change & $3.00 \pm 0.81^{*}$ & $0.63 \pm 0.59$ \\
\hline
\end{tabular}

*indicates a significant difference between before and after, **indicates a significant difference between the two groups, $\mathrm{p}<0.05$. PTA: paralyzed side tibialis anterior muscle, PMG: paralyzed side medial gastrocnemius, AFO: ankle foot orthosis. Comparison within the group and comparison between the groups were made using the paired sample t-test and the independent sample t-test, respectively.

\section{RESULTS}

Muscle activity prior to and after the balance training was compared between the AFO and shoes group. Muscle activity of the tibialis anterior muscle of the affected side of the AFO group decreased from $19.93 \pm 4.85 \%$ prior to the balance training to $16.71 \pm 3.88 \%$ after the balance training and muscle activity of the medial gastrocnemius muscle of the affected side increased from $23.65 \pm 8.10 \%$ prior to the balance training to $26.64 \pm 5.83 \%$ after the balance training, and both differences were significant $(p<0.05)$. Muscle activity of the tibialis anterior muscle of the affected side of the shoes group decreased from $20.26 \pm 3.83 \%$ prior to the balance training to $20.23 \pm 3.49 \%$ after the balance training and muscle activity of the medial gastrocnemius muscle of the affected side increased from $24.87 \pm 4.59 \%$ prior to the balance training to $25.51 \pm 5.11 \%$ after the balance training; neither of the differences was significantly different. There was a significant difference in the muscle activities of the tibialis anterior muscle of the affected side between the AFO and shoes groups $(p<0.05)$ (Table 3$)$. Stability indexes prior to and after the balance training between the AFO and shoes group were compared. For the AFO group, the stability index in a standing position with eyes open (NO) decreased from $25.72 \pm 2.98$ prior to the balance training to $24.07 \pm 2.90$ after the balance training, the stability index in
Table 4. Comparison of the stability index between the two groups

\begin{tabular}{|c|c|c|c|}
\hline \multirow{2}{*}{\multicolumn{2}{|c|}{ Condition }} & \multicolumn{2}{|c|}{ Group } \\
\hline & & \multirow{2}{*}{$\begin{array}{c}\text { AFO Group }(n=13) \\
\text { Mean } \pm \text { SD } \\
25.72 \pm 2.98\end{array}$} & \multirow{2}{*}{$\begin{array}{c}\text { Shoes Group }(n=12) \\
\text { Mean } \pm \text { SD } \\
22.45 \pm 4.31\end{array}$} \\
\hline \multirow{3}{*}{ NO } & Pre- & & \\
\hline & Post- & $24.07 \pm 2.90$ & $21.05 \pm 4.19$ \\
\hline & Change $^{* *}$ & $-1.65 \pm 0.74^{*}$ & $-1.40 \pm 0.80^{*}$ \\
\hline \multirow{3}{*}{$\mathrm{NC}$} & Pre- & $35.37 \pm 7.19$ & $31.57 \pm 9.28$ \\
\hline & Post- & $34.08 \pm 6.93$ & $30.52 \pm 10.04$ \\
\hline & Change & $-1.29 \pm 1.35^{*}$ & $-1.05 \pm 3.22$ \\
\hline \multirow{3}{*}{$\mathrm{PO}$} & Pre- & $30.13 \pm 5.64$ & $28.03 \pm 6.01$ \\
\hline & Post- & $29.57 \pm 5.95$ & $27.01 \pm 6.03$ \\
\hline & Change & $-0.56 \pm 0.59^{*}$ & $-1.02 \pm 1.20^{*}$ \\
\hline \multirow{3}{*}{$\mathrm{PC}$} & Pre- & $38.80 \pm 6.70$ & $32.37 \pm 7.51$ \\
\hline & Post- & $35.76 \pm 6.38$ & $32.25 \pm 7.26$ \\
\hline & Change & $-3.05 \pm 1.75^{*}$ & $-0.13 \pm 1.40$ \\
\hline
\end{tabular}

*indicates a significant difference between before and after, **indicates a significant difference between the two groups, $p<0.05$. NO: normal open, NC: normal close, PO: pillow open, PC: pillow close, AFO: ankle foot orthosis. Comparison within the group and comparison between the groups were made using the paired sample t-test and the independent sample t-test, respectively.

a standing position with eyes closed (NC) decreased from $35.37 \pm 7.19$ prior to the balance training to $34.08 \pm 6.93$ after the balance training, the stability index in a standing position on the pillow with eyes open (PO) decreased from $30.13 \pm 5.64$ prior to the balance training to $29.57 \pm$ 5.95 after the balance training, and the stability index in a standing position on the pillow with their eyes closed (PC) decreased from $38.80 \pm 6.70$ prior to the balance exercise to $35.76 \pm 6.38$ after the balance exercise. All differences were significant $(p<0.05)$. For the shoes group, the stability index showed significant decreases from $22.45 \pm 4.31$ to $21.05 \pm 4.19$ in NO, and from $28.03 \pm 6.01$ to $27.01 \pm 6.03$ in PO $(\mathrm{p}<0.05)$. Regarding changes in stability index resulting from balance training, there was a significant difference in NO between the AFO group and the shoes group $(p<0.05)$ (Table 4). 


\section{DISCUSSION}

This study examined the effects of ankle-foot orthosis during balance training of chronic stroke patients on muscle activities and static balance of the lower limbs of stroke patients. After the six weeks of balance training, the data of the two groups were compared to examine muscle activities and static balance around the ankles related to wearing of the ankle-foot orthosis. The stability index was significantly different in the NO condition between the groups, and the AFO group showed statistically significant differences in all conditions between prior to and after the balance training. The changes in AFO group muscle activities were significantly greater than those of the shoes group.

After balance training with the ankle-foot orthosis, there was no significant difference in the medial gastrocnemius muscle activity of the affected side, but there was a significant difference in the tibialis anterior muscle activity of the affected side. During balance training with the ankle-foot orthosis, the muscle activity of the tibialis anterior muscle of the affected side decreased and the muscle activity of the medial gastrocnemius muscle increased. However, in the group without the ankle-foot orthosis, there was no prepost statistically significant difference in either the muscle activity of the tibialis anterior muscle or the medial gastrocnemius muscle of the affected side. This result is consistent with a study in which the ankle muscle activities of nine males and one female in a static standing posture were examined, and the use of the ankle plantar flexor was predominant ${ }^{18)}$. It is also in agreement with a study in which the anterior-posterior center of pressure of six multiple sclerosis patients and four ordinary subjects were examined in a standing position and the use of the gastrocnemius was predominant ${ }^{19)}$. However, an ankle-foot orthosis used postural adjustment by 42 stroke patients whose onset of a stroke was 6 months prior or earlier, and 61 stroke patients whose onset of a stroke was 12 months ago or longer, was effective at providing stability for the ankle of early phase stroke patients but not chronic phase stroke patients, as structural changes has occurred, including changes in alignment and muscle shortening ${ }^{20)}$.

There was a statistically significant difference in the stability index of NO between the AFO and shoes group, but there were no statistically significant differences in $\mathrm{NC}, \mathrm{PO}$, and $\mathrm{PC}$ between the two groups. In the group who wore the ankle-foot orthosis, there were significant differences in the stability indexes of $\mathrm{NO}, \mathrm{NC}, \mathrm{PO}$, and $\mathrm{PC}$, and in the group who wore only shoes, there were significant differences in NO and PO. This result is similar to that of study in which postural sway of 28 stroke and traumatic brain injury patients was measured with and without an ankle-foot orthosis; when the ankle-foot orthosis was worn, postural sway was small ${ }^{2}$. Our results are also consistent with those of a study in which balance maintenance of 11 stroke patients and 10 ordinary subjects wearing an ankle-foot orthosis was examined: weight shift to the lateral side and an increase in weight bearing on the affected side resulted in more use of an ankle strategy than a hip strategy for stability $^{4}$. In the rehabilitation process of stroke patients, improvement of balance ability is important. In prescribing orthoses, improvement in balance ability and gait should be considered. In general, use of an ankle-foot orthosis may be helpful for some stroke patients' balance, but stroke patients differ in degree and area of anatomical damage. Therefore, changes must be made in accordance with their environment and condition. Balance training variables appropriate for patients should be selected, and effective treatment methods should be utilized to maximize patients' potential capabilities. Generalization of this study is limited, as only those patients meeting the selection criteria were examined. Future research that includes the same kind of patients with classification of etiology and brain lesions is necessary.

\section{REFERENCES}

1) Ikai $T$, Kamikubo $T$, Takehara I, et al.: Dynamic postural control in patients with hemiparesis. Am J Phys Med Rehabil, 2003, 82: 463-469. [Medline] [CrossRef]

2) Pohl M: Mehrholz: Immediate effects of an individually designed functional ankle-foot orthosis on stance and gait in hemiparetic patients. Clin Rehabil, 2006, 20: 324-330. [Medline] [CrossRef]

3) Yavuzer G, Eser F, Karakus D, et al.: The effects of balance training on gait late after stroke: a randomized controlled trial. Clin Rehabil, 2006, 20: 960-969. [Medline] [CrossRef]

4) Chen CK, Hong WH, Chu NK, et al.: Effects of an anterior ankle-foot orthosis on postural stability in stroke patients with hemiplegia. Am J Phys Med Rehabil, 2008, 87: 815-820. [Medline] [CrossRef]

5) Kerrigan DC, Karvosky ME, Riley PO: Spastic paretic stiff-legged gait: joint kinetic. Am J Phys Med Rehabil, 2001, 80: 244-249. [Medline] [CrossRef]

6) Salbach NM, Mayo NE, Wood-Dauphinee S, et al.: A task-orientated intervention enhances walking distance and speed in the first year post stroke: a randomized controlled trial. Clin Rehabil, 2004, 18: 509-519. [Medline] [CrossRef]

7) Eser F, Yanvuzer G, Karakus D, et al.: The effect of balance training on motor recovery and ambulation after stroke: a randomized controlled trial. Eur J Phys Rehabil Med, 2008, 44: 19-25. [Medline]

8) Esquenazi A, Ofluoglu D, Hirai B, et al.: The effect of an ankle-foot orthosis on temporal spatial parameters and asymmetry of gait in hemiparetic patients. PM R, 2009, 1: 1014-1018. [Medline] [CrossRef]

9) Brantingham JW, Gilbert JL, Shaik J: Sagittal plane blockage of the foot, ankle and hallux and foot alignment-prevalence and association with low back pain. J Chiropr Med, 2006, 5: 123-127. [Medline] [CrossRef]

10) Horak FB, Shupert CL, Mirka A: Components of postural dyscontrol in the elderly: a review. Neurobiol Aging, 1989, 10: 727-738. [Medline] [CrossRef]

11) Carlson WE, Vaughar CL, Damiano DL, et al.: Orthotic management of gait in spastic diplegia. Am J Phys Med Rehabil, 1997, 76: 219-225. [Medline] [CrossRef]

12) Gatev P, Thomas S, Kepple T, et al.: Feedforward ankle strategy of balance during quiet stance in adults. J Physiol, 1999, 514: 915-928. [Medline] [CrossRef]

13) Daubney ME, Culham EG: Lower extremity muscle force and balance performance in adults aged 65 years and older. Phys Ther, 1999, 79: 11771185. [Medline]

14) Wolfson L, Judge J, Whipple RH: Strength is a major factor in balance, gait, and the occurrence of falls. J Gerontol A Biol Sci Med Sci, 1995, 50: 64-67. [Medline]

15) Kohen-Raz R: Application of tetra-ataxiametric posturography in clinical and developmental diagnosis. Percept Mot Skills, 1991, 73: 635-656. [Medline] [CrossRef]

16) Almeida GL, Carvalho RL, Talis VL: Postural strategy to keep balance on the seesaw. Gait Posture, 2006, 23: 17-21. [Medline] [CrossRef]

17) Horak FB: Effects of neurological disorders on postural movement strategies in the elderly. Elsevier, 1992.

18) Masani K, Sayenko DG, Vette AH: What triggers the continuous muscle activity during upright standing? Gait Posture, 2013, 37: 72-77. [Medline] [CrossRef]

19) Borg F, Finell M, Hakala I, et al.: Analyzing gastrocnemius EMG-activity and sway data from quiet and perturbed standing. J Electromyogr Kinesiol, 2007, 17: 622-634. [Medline] [CrossRef]

20) Wang RY, Yen L, Lee CC, et al.: Effects of an ankle-foot orthosis on balance performance in patients with hemiparesis of different durations. Clin Rehabil, 2005, 19: 37-44. [Medline] [CrossRef] 